\title{
Electronic Vote at Geography Election Iran
}

\author{
Rahmat Zolfaghari \\ Islamic Azad University \\ Hashtgerd Branch, \\ Department of Computer Engineering, \\ Tehran, Iran
}

\begin{abstract}
The first official election, held in 509 BC in Greece. The population grew gradually more and more the need to expand democracy. With the advent of the new government to implement democracy, the need to structure the "Republic" The system was created. Democracy ways to implement the goals, ideals And And its intentions that the most important use of election and the majority of public opinion is referring to.

The world's population of 1.5 billion people in 1914 to 7 billion reached in recent years, the population increased seven-fold over a century, and on the other hand the growing influence of technology in human life require the vote, as well as many others government activities to be carried out electronically. E of the most important pillars of democracy, namely elections, could be an appropriate way to move towards a system of social health. This requires a long process to get it done without the knowledge of geography, demographics and the election is not possible.
\end{abstract}

\section{Keywords}

vote, Geography Election, Vote Electronic,

\section{INTRODUCTION}

Population heterogeneity in the national unevenly ethnic, cultural, religious, ethnic and tribal defined, one of the main variables in the population of a country setting. [1] The biodiversity of the desert, desert, jungle, mountain. .. and climate variability include issues such as the intensity of heat and rainfall convergence in the distribution or population of a region have a key role. In addition to issues related to agricultural production, economic growth, development and quality of life indicators, in turn, on how Development and population density influence. [2]

Factors such as low population areas impassable, and mobile ballot boxes .... cause to the possibility of holding all the elections in all the main branches are not electronic. [3] It should be provided with sufficient knowledge of geography as much as possible solutions to the electronic elections forward. In the event of the implementation of the plan would also increase the administrative security, but should adopt policies that This change in the electoral system, reduce participation and also increase operating costs are not excessive. [4]

In Iran, on average, an election every year and runs the number and proportion of the population compared with the rest of the world is important. [5] In any case, it should also bear in mind that the goal to achieve the best possible condition for the conduct of the election could be an important contribution to the progress of democracy in the country. The main objective of this paper is to provide a platform for the implementation of low-cost Electronics will be no reduction in election turnout.
In this paper we examine the geography of the demographic, economic, natural and electoral According to the data released by the provincial sites, organization Record Status Iran, the Interior Ministry and Centre Statistics Iran to simulate the conditions and problems encountered in the implementation of electronic elections The Look.

\section{CAUSES THE NEED FOR THE IMPLEMENTATION OF ELECTRONIC VOTING}

In Iran, the government, parliament and municipalities, takes place every four years. Thus, the single decision-making, implementation and legislation to be together for a long period in government Men leave. In many countries, in addition to the large, sensitive government decisions also help people decide Used. For example, voting for separation from Great Britain can be Scotland Be an example of these elections is that the leaves of the September 1393. All Press the Independence Catalonia or in Spain, all Press the Law On the Syria is, all Press the At Switzerland SA For Pay Subsidized The \$2,800 At Month, All Press the At Case Return Of the Jacks or To Use From Energy Core Of the referendum Crimea The transfer from Ukraine to Russia and all Press the Law On the Europe At Samples from these cases are French. [6] Although in this type of participation in decision making only twice, in April and December 1358, called for " All of the press System President of Islam or Iran "and" All the press Law On the President of Islamic The Iran "took place, but a high diversity of other electoral models in the country.

Internet or electronic voting systems at the national level, often against the business processes, with the aim of reducing the economic costs of not Fall. [7] But the main purpose of this change is to create a secure high speed. Speed up the preparation team for immediate elections in exceptional cases such as the death of the president of a country, will play a decisive role in the country's political stability. [8] The practice of democracy is at a high level that people expected. Holding fair and transparent elections are the most important factors to achieve a democratic system is ideal. [9] Today, with the development of electronic systems and protocols and voting equipment, is still expected transparency in the implementation of electronic elections has not been established. Hence the need to vote in different aspects of the review to the solution of the Remove error in the elections. [10]

In such a situation would be any plan for implementing a secure elections, can not be discussed. In this paper, a project to create a voting room, to provide the possibility of counting the vote, provided Online vote of the moment . room digital safe polling can be used along with traditional 
implementation. For many consider the project requirements, which are discussed in detail in the next section.

\section{THE CREATION OF ELECTRONIC VOTING ROOMS}

The plan will be presented for election, to a certain demographic areas applicable. [11] Plan to make room for voting, allowing the majority of people at the foot of electronic voting systems in the event of a referendum or other electoral model provides. An example of electronic voting equipment and the room is shown in Fig. Although the possibility of creating the room for electronics in some areas with low population or difficult terrain there, but you can get accurate statistics on the number of eligible voters, polling permanent room to a number of requirements in different regions of each province established. [12]

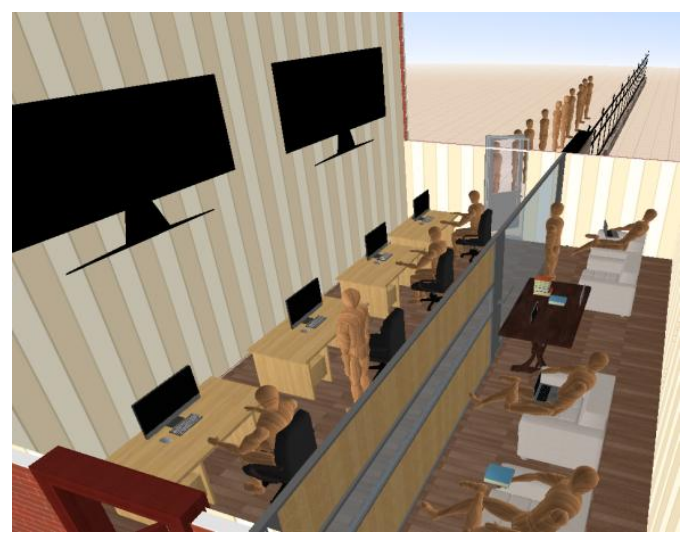

Fig 1: A perspective view of the room to see birds of electronic voting

To implement this plan, we need to establish some specific conditions. In some cases, making some of the conditions outlined in this article require ratification by parliament of the law Or government Investment Is. [13] General Terms projects polling room includes default rules that in most countries in the world are established. Location and construction of this room voting process is complicated by

the population of each province, in two separate areas studied:

1. Number of rooms required voting in each province:

With the exact number of electoral geography of the polling stations and ballot boxes as well as the number of branches and the traditional system, it can be estimated that for each province, the number of branches (room) electronic voting is needed.

2. Location of electronic voting room:

By specifying the number of polling stations needed to determine the best location possible location for the construction of the polling room due to the geographical situation and climate will be important. Location, rooms, electronic voting should be done in a way that does not reduce people's participation in elections. In the next section, affecting the role of geographical factors in choosing the appropriate number and location of electronic voting room here.

\section{THE RATIO OF THE NUMBER OF BALLOT BOXES TO THE POPULATION}

Check the statistics of the number of votes in polling stations in the past period can be specified factor is to determine the location of polling stations is created. This section reviews the four indicators of the population, the population eligible to vote, The number of ballot boxes and the projected area of the Ninth Round of Parliament To discuss the results. [14]

Table 1 - Statistical Report on the six major indexes in the Ninth Parliament

\begin{tabular}{|c|c|l|c|c|c|c|}
\hline & Population & $\begin{array}{l}\text { Eligible } \\
\text { population } \\
\text { Circumstanc } \\
\text { es } \\
\text { to vote }\end{array}$ & $\begin{array}{l}\text { The number of } \\
\text { ballot boxes } \\
\text { forecasts }\end{array}$ & $\begin{array}{l}\text { On average } \\
\text { for each } \\
\text { Fund N N } \\
\text { the eligible }\end{array}$ & $\begin{array}{l}\text { Area } \\
\text { Region } \\
\text { km2 }\end{array}$ & $\begin{array}{l}\text { population } \\
\text { density }\end{array}$ \\
\hline Qom & 1151672 & 763814 & 585 & 1306 & 11526 & 66 \\
\hline Tehran & 12183391 & 8878545 & 6300 & 1409 & 12981 & 683 \\
\hline Gilan & 2480847 & 1815597 & 2500 & 726 & 14042 & 177 \\
\hline Khuzestan & 4531720 & 2872894 & 3809 & 754 & 64055 & 44 \\
\hline Esfahan & 4879312 & 3905641 & 2320 & 1683 & 107102 & 36 \\
\hline North Khorasan & 867727 & 555987 & 702 & 792 & 28434 & 19 \\
\hline Khorasan Razavi & 5994402 & 3915821 & 3091 & 1267 & 128949 & 30 \\
\hline Kerman & 2938988 & 1753018 & 1939 & 904 & 181785 & 9 \\
\hline Mazandaran & 3073943 & 2231513 & 2000 & 1116 & 23842 & 93 \\
\hline
\end{tabular}


Province set forth in Table 1 With regard to climate Of Weather And Aerial Iran and the country's dominant ethnic group have been selected, as well as the fact that the number of ballot boxes and branches in some provinces officially yet, so we were somewhat Choose the desired limits. The information contained in table 1 Can be drawn the following conclusions:

\subsection{Increase The Number Of Ballot Boxes In Deprived Areas}

With the condition of North Khorasan, Khuzestan, Kerman to the conclusion that common features of these provinces The number of ballot boxes to the proportion of the population is eligible. In terms of the provinces, a common factor called factor deprivation and underdevelopment obtains. The very number of provinces 3 full-scale development 5 are, in the absence of provinces like Tehran and Isfahan Rated 5 and other provinces in the table 1 Rated 4 respectively. 1

According to voter turnout in elections in Tehran and Isfahan, respectively, against 64 and 59 per cent as well as in the provinces of Khuzestan and Khorasan and Kerman, 56, 64 and 78 percent are, To the conclusion that the ban on direct role Determining the increase or decrease in the participation rate is. The poem will be another factor determining voting in deprived areas. Although economic deprivation does not affect the turnout, but always in the options disadvantaged areas play a decisive role in determining the outcome of elections or political geography ie to the elections, including families with annual income lower rate 50 thousand dollars in America noted, in competition with groups of up to 100 thousand dollars, managed to select your preferred option for the 2012 America President Ray rides were..2

The international experts believe that the separation of macro-development policies and strategies, in particular, and Set in the rural development and eradication of widespread poverty that govern them, pay. In contrast, although many governments, extensive and costly programs have done to improve the infrastructure, but the evidence indicates that this alone could not solve the problems of rural life.

Therefore, to conclude that the lack of proper infrastructure and also economic deprivation, the province's population convenient access to polling stations difficult, so we need to for the welfare of voters and also maintain maximum participation contact and easy access for all people, in the deprived provinces of the number of ballot boxes and polling stations used.

\subsection{The Impact Area Of The Province In The Number Of Ballot Boxes}

Three indicators of population, expansion of cities in each province, as coefficients to determine the number of ballot box can be considered. For example, if the total area of the province to consider, an average of 36 people per square kilometer of vote with voters, while the proportion for the province with an area of almost 2-fold and a population of less than half of the province to 9 people per square kilometer of voters. There are approximately 1.5 times the number of boxes in the province shows that the climate in

1. According to Security Administration and Manpower Development, Ministry of Health and Medical Education in 1393

${ }^{2}$ - http://edition.cnn.com/election/2012/results/state/FL/president
Iran Population parameter impact factor in determining the number of funds is more effective than the area of the province.

In a preliminary study, with elections for the two provinces with different size and the same population we studied. According to data extracted from Table 1, the Mazandaran province and has a population of approximately 3 million persons. While the province is eight times the size of the province, The number of ballots in the province of Mazandaran province is only 1.2 times. This shows the extent of the low coefficient has an impact on the number of polling stations.

The above statistics the number of city and county can be considered, in this review of the year 1390 the city of Kerman province in Orzooiyeh, Pomegranate, Texture, Bardsir, Bam, Jiroft, Rubber, Raver, Rafsanjan, ROODBAR South, Reagan, Zarand, Sirjan, City Babak, Anbarabad, Faryab, Fahraj, Castle treasure, Kerman, Kuhbanan, Kahnuj, Manoujan, In the same year the city of Amol, in Mazandaran province Normashir, Babylon, Babolsar, to city, Branch, Brook, Chalus, Ramsar, Surrey, Access, Phoenix, Abbas Abad, Fereydunkenar, Vice City, Bottlenecks, Mahmudabad, Among Dorud, Neckar, Light, has been Noshahr.

According to what was said, the province's 62 cities, which in turn are a subset of the 23 city, including 54 city and province is in the form of 20 cities. This shows that different weather conditions and the extent incomparable with each other, the city is directly related to the number of polling stations, The close relationship between the number of population in the two provinces is established, The province with a population of 4 million, 95 city. However, this is not the totality of the city like Tehran (the capital due to special circumstances) or province (because of Arab ethnicity and families with a large population) number The cities have a decisive role in the number of funds. detailed study of urbanization and rural and nomadic life can determine the number of polling stations in each province have an important role.

In the 1390 parliamentary elections in Tehran province with an area of about 13 thousand cubic meters, 6,300 ballot boxes, and in Isfahan province with an area of 107 thousand cubic meters in Kerman area of around 2,300 funds and 181 thousand square meters, about 2,000 ballot boxes Is placed., Which shows that the problem of big capital in the first and second grade, along with the population, the extent of its impact factor has overshadowed the vote to determine the number.

Khuzestan province with a population of about a million less than the population of the province is large, has a more ballot boxes, that this is due to less dispersion of the population in big cities and also the large number of children and adolescents in Khuzestan province is. The fact that the population of the two provinces are equal to the year 1395 , the role of the changing needs of the province's population of children and adolescents. Therefore, to design a system that meets the needs of the future, have a comprehensive view on the process demographic changes the province.

\subsection{Tasyrshakhs Density Relative The Number Of Ballots Population}

One From Index And Important Population That At Program PLANNING And And Treatment Country From It Use And 
To be; Index Density Relative Population.3 This Index From Assigned Number Population To Area Calculation And The . Distribution Inharmonious Population Cause And The Up to At Some From Areas Density Slight And In some Others Density Severe Population Created Is

State Gilan With 14042 Km Square, Close To 0.9 area Earthen Country There And From The Perspective At Rank 29 Country The And Recommended. The Region From The smallest Provinces Country Considered And The . Gilan With This Low area, about 3.4 percent of the population is in place. As shown in Table 1 It can be seen, in Tehran, with a population density of 683 Persons per square kilometer of area, population density and the provinces of Gilan and Mazandaran has ranked first respectively second and third respectively.

Given that, according to the 1390 population and housing census, the average density in the country is 49 per square kilometer, Gilan Province and Tehran's 3.5 times to 14 times the average population density in the cover. The conditions that if the land is under cultivation of this area are deducted, the density increases sharply. High population density are among the factors that require a lot of funds are created in the province. It needs to take the province in Table 1 after Tehran and major cities of Khuzestan, Isfahan and Khorasan most polling stations is. In addition to high density, can be the weather conditions and specific conditions and impassable rural roads in the forests and mountains of the province of the other factors that need to know more of the ballot box.

To determine the number of ballot boxes can also be used for international statistics. For example, given that Tehran. At However, Present Sixteenth City Full Density The world, the The number of ballot boxes in the city In other countries with similar population density, with the participation of the country as appropriate parameters considered to determine the effect of population density. For example, countries in Northeast Guyana South America with a population of about 800 thousand people, has 42076 is the ballot box, according to the area of 214970 square kilometers, the population density is 3.72 .

At Continue density compared to the city of Herat in Afghanistan with 177 thousand inhabitants and an area of 54022 square kilometers and the number of ballot boxes in 1515 with the city of Kandahar (Afghanistan's third city of High Density) With approximately 201 thousand inhabitants and an area of 54778 square kilometers and the number of the ballot box in 1082, with a population density 3.2 Pay. The statistics show that less density in the same area, the need for additional funds requires number.

New York City to Speak Cloud City World Is, Contains 7 thousand And $900 \mathrm{~km}$ Square The total area And Population That At Living The Now the de Too Less From 9 Million Person Is. Beijing Fourth City Full Population World Title The And Contains Population of about 12 million Is. However, detailed information on the number of ballot boxes in these countries is not available, but a different voter turnout in the election can be a good approximation of the number of votes obtained. Karachi, Shanghai, Mumbai , Buenos Aires, Seoul Moscow and other cities are densely populated that the study on issues related

3 - Population Density

4- According to information published on the site http://www.gecom.org.gy to the ballots in this city can be an important aid in the prediction of high-density data of the fund in the province of Iran.

\section{CONCLUSION}

Governments seek to carry out a lot of paperwork and bureaucracy elimination of Waste Administrative, although it is in the economy such as banking or training such as virtual university scholar, but an integrated plan has not been implemented in the country to carry out election-mail. This is due to the need for security is up to run the scheme, making this election security without understanding the geography of elections is not possible.

In this paper we examine the statistics on the number of ballot boxes, vote number and proportion of voters in different provinces of Iran's ninth Majlis elections And compare them with different population according to Census 1390 Important factors in determining the number and location of branches of electronic voting discussed. In an overview of this study was to evaluate the effect of three components of the size, density Relative Populations and underserved areas in the elections separately discussed and the role of each in determining the number of branches of electronic voting, we have analyzed.

With the knowledge gained, it is suggested that the government plans to implement electronic voting room as a factor in the rise of democracy, its best used. The implementation of this project, in addition to requiring extensive studies of climate, the knowledge of changes of the population's needs. It is also recommended to new components that can be effective in the implementation of electronic elections, has been studied so that a comprehensive plan with the lowest handicap, electronic elections in the country is we can run. Naturally, electronic elections at intervals shorter affordable cost, the greater participation of citizens in the country will be critical decisions, and this realization will provide the highest level of democracy.

\section{REFERENCES}

[1] Masoud Rezaei Sharif Abadi; Abbas Salimi Namin, Seyyed Mousa Hashemi Tabar, the I : Details of, scenarios And Achievements, beach Thought Tehran, 115-110.

[2] The exhibitions of the individual, Z., as of the 1372 , the geography of the election, magazine Research Of the geography of the Yi - No. 33 .

[3] Meaning Kaviani, geography election With Emphasis On Election President Republic At Iran University of Khwarizmi, 75-10

[4] Gholamreza Khoja survey, Ali Akbar warrior, MM legislator, history Political Election President Republic Islamic Iran, the Institute of Studies Cultural And Social, 244-220, 13, 92 .

[5] A. Ahmadi Elections At Iran ( Survey Legal And Law ) , the amount, 135-120, 13, 89 .

[6] Majid Bozorgmehri, 13, 90 , no On Laws And Role Parties Political At Elections in France, righteous book, 385-380.

[7] D. Balzarotti, G. Banks, M. Cova, "An Experience in Testing the Security of Real-World Electronic Voting 
Systems", IEEE Transactions on Software Engineering, Vol. 36, pp. 453 - 473, May 2010.

[8] SM Jambhulkar, JB Chakole, Prpardhi, "A Secure Approach for Web Based Internet Voting System Using Multiple Encryption", International Conference on Signal Processing and Computing Technologies (Icesc), vol 4, pp. 371-375, jan 2014.

[9] Dix A., "Electronic democracy and its implication for political privacy", 23rd International Conference of Data Protection Commissioners, September 2001, Paris.

[10] Crown Neyshabouri, N., and Ali Akbar Jalali, 1388 , electronic voting security requirements in electronics, Second International Conference on Electronic city, Tehran, Institute of Information and Communication Technology (SID), the Municipality of Tehran.

[11] Faraj Ali Mousavi, 13, 89 , N. A. Mahdavi Rad, managing elections, Information, 304-270.
[12] Abdulmutallab Abdullah Analysis Behavior Voting report At Iran ( the case of citizens of Tehran At Election Year 1388 - 1387), University of Imam Honest ( AS ), 365-330, 13, 92 .

[13] Hasan Khosravi, 13, 88 , rights, elections, democratic ( principles, principles And Pattern Favorable Of the Parliament, again, 425-410.

[14] Mars is the power of God, Winter 1390 , the Ninth Assembly of the Council of Islamic, opportunity And And Damage and the probability of the magazine : the coach , No 39 (19 pages - from 44 to 62 )

[15] Ghamami, political, D Mohammad Cradle of the template of the Provincial Assembly of the Council of Islamic And System of quantitative million national elections Journal : Hearing " stamp And November 1390 - No. 88 (6 pages - from 35 to 40 ) 